\title{
The poor children of the poor: Coping with diabetes control in a resource-poor setting
}

\author{
F P R de Villiers, PhD, FACP, FCPaed, MMed (Paed) \\ Department of Paediatrics and Child Health, MEDUNSA Campus, Sefako Makgatho Health Sciences University, Pretoria
}

Corresponding author: F P R de Villiers (alfafrancois@yahoo.co.uk)

\begin{abstract}
Background. Coping with diabetes control is difficult for newly diagnosed and experienced patients alike. Children with diabetes face severe challenges, as they may not yet have attained the necessary cognitive, fine motor or psychosocial skills required for performance of the tasks required from the diabetic patient. Most therefore require some adult assistance.

Objectives. To establish whether paediatric diabetic patients are adequately supported by their families in terms of giving insulin injections and doing home blood glucose monitoring (HBGM), and whether insulin and the necessary equipment are appropriately stored in their homes. Methods. Patients attending a paediatric diabetes clinic were interviewed. The data collected included demographic variables, type of insulin, measurement of insulin doses, administration of insulin, and blood glucose monitoring tests.

Results. Twenty-five subjects were interviewed: 18 measured the insulin themselves, five mothers and one aunt did so, and in one case the mother and patient did so together. The four children aged $\leq 10$ years had their insulin measured by their mothers, but one had to administer the injection himself. Eight of the nine children aged 11 - 15 years measured and administered the insulin themselves; in four cases the doses were checked by an adult. The mothers of four children did the fingerpricks, and eight children were helped with measuring the results. Only two children aged 11 - 15 years had their doses checked by an adult.

Conclusion. Adult assistance with regard to both insulin injections and HBGM is rarely forthcoming. The children seem not to be sufficiently supported by their families.
\end{abstract}

S Afr Med J 2015;105(5):397-399. DOI:10.7196/SAMJ.8496

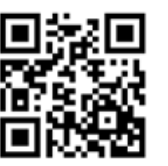

Coping with diabetes control is difficult for newly diagnosed and experienced patients alike. The child is often critically ill at diagnosis, and the child and the family are faced with a lifelong condition, as well as loss of the child as he/she used to be. All suddenly face complex technical challenges. ${ }^{[1]}$ Later, the constant repetition of testing and insulin administration, unremitting dietary vigilance and careful adjustment of every aspect of living with the disease potentially become wearisome..$^{[1,2]}$

Many children over the age of 10 years administer their own insulin injections, ${ }^{[3]}$ although some authorities believe that the parents should take complete control up to the age of puberty, i.e. about 13 or 14 years. ${ }^{[4]}$ However, children vary in their development and with regard to the age at which self-treatment is appropriate. ${ }^{[3]}$ Parents should not expect that children will continue self-injection without parental interest and guidance, and will sometimes find themselves having to take over the injections again. ${ }^{[3]}$ It must be noted that some patients store insulin inappropriately, measure it incorrectly, and neglect home blood glucose monitoring (HBGM).

Multiple re-use of disposable insulin syringes for six injections is common, the practice being supported by a study in which syringes were re-used an average of 6.3 times without infections. ${ }^{[5]}$ In Bangladesh, syringes were used 31.3 times on average (maximum 120 times). ${ }^{[6]}$

In contrast to the vast literature on the biology of diabetes mellitus, little is written on the practical aspects of diabetes care. We undertook a study in our clinic at the Dr George Mukhari Academic Hospital, Pretoria, South Africa, to establish whether insulin and the other necessary equipment are appropriately stored in the homes of diabetic patients, and whether paediatric diabetic patients are adequately supported by their families.

\section{Methods}

Patients attending the paediatric diabetes clinic were interviewed by a mother-tongue Tswana speaker in English or Tswana, depending on the patient's preference. Interviews were conducted on the clinic day before the patient's consultation, in a private room, and took about 15 minutes. Questions included demographic variables, the type of insulin and injection system and where these were kept, the measurement of insulin doses, insulin injections and blood glucose monitoring tests. Permission for the study was granted by the MEDUNSA Research Ethics Committee, MEDUNSA campus, University of Limpopo (now Sefako Makgatho Health Sciences University), and informed consent was obtained from all subjects. Patients could withdraw at any time without its affecting their therapy or relationship with the clinic staff, and all information was confidential.

\section{Results}

Twenty-five subjects were interviewed: nine boys and 16 girls, aged 7 - 18 years. The majority (19) were teenagers, four were aged $\leq 10$ years and two were between 11 and 12 years old. The duration of diabetes ranged from 1 month to 9 years, with a median of 4 years. Two patients had had diabetes for 1 - 3 months, four for 1 - 2 years, 12 for 2 - 5 years, and seven for $>5$ but $<10$ years.

Glycosylated haemoglobin (HbAlc) values (Table 1) in the study subjects were generally unsatisfactory: only two were in the normal range, five were slightly elevated, eight fell in the range $9-11.9 \%$, and five were $>12 \%$ (in five cases no value could be found). There was a tendency for better controlled HbAlc to correspond with a shorter duration of diabetes (not statistically significant; $p=0.151$ ). Twothirds of the patients with a duration of diabetes of $<2$ years had an HbA1c level $<9 \%$, while only $21 \%$ of those with a longer duration of diabetes had similar $\mathrm{HbAlc}$ values. 
The majority of the patients $(20,80 \%)$ were on twice-daily injections with a premixed insulin formulation (Actraphane); this included all the preteens. Four patients administered three injections per day: Actraphane before breakfast, soluble insulin (Actrapid) before supper, and isophane insulin (Protaphane) at $21 \mathrm{~h} 00$, and only one was on a basal-bolus regimen (isophane insulin at $21 \mathrm{~h} 00$ hours, with soluble insulin boluses before each meal).

All the households had a refrigerator, and none stored insulin in the freezer compartment. At night $88 \%$ of the subjects kept the insulin in the refrigerator, while more than half $(56 \%)$ did so during the day (Table 2 ). Nine of the subjects (36\%) usually carried their insulin with them during the day, while $12(48 \%)$ never did so (Table 3). Eight of those who usually carried the insulin with them replaced it in the fridge on returning home. Three of the patients who were on three injections a day did not take insulin to school; only one on triple injections and the one on basal-bolus therapy did so.

Eighteen of the 25 patients measured the insulin themselves, while five mothers did so. In one case the duties were shared between the mother and the child, and in the last, an aunt measured the insulin. The four children who were aged 10 years or younger were assisted by their mothers, but one of these had to administer the injection himself. Eight of the nine children aged between 11 and 15 years measured and administered the insulin themselves; in four cases the doses were checked by an adult. Altogether, 18 children measured the insulin themselves and 20 administered the injection themselves; in all cases the doses were never checked. In only seven cases were the doses ever checked by another (Table 4).

Regarding HBGM (Table 5), 14 subjects did fingerpricks themselves. The mother did this in four cases, and one child assisted his mother. About a quarter of the sample (six patients) did not perform HBGM at all. Measuring and recording the results followed approximately the same pattern: only five of the 19 patients were assisted by an adult in the fingerpricks, eight with measuring the results, and four with the recording of their results.

Blood glucose control, as measured by $\mathrm{HbAlc}$ values, was compared between the children who had some assistance (in injection, HBGM or both) against those who had no help. There was no statistically significant difference between the two groups.

The measurement of insulin was demonstrated to the interviewer by 11 of

Table 1. HbAlc values correlated with duration of diabetes ${ }^{\star}$

\begin{tabular}{|c|c|c|c|c|c|}
\hline \multirow[b]{2}{*}{ Duration } & \multicolumn{4}{|c|}{ HbAlc (\%) } & \multirow[b]{2}{*}{ Total, $r$} \\
\hline & $<7, n$ & $7-8.9, n$ & $9-11.9, n$ & $>12, n$ & \\
\hline $1-3$ months & 0 & 0 & 0 & 1 & 1 \\
\hline $1-1.9$ years & 2 & 2 & 0 & 1 & 5 \\
\hline $2-5.9$ years & 0 & 1 & 5 & 2 & 8 \\
\hline $6-10$ years & 0 & 2 & 3 & 1 & 6 \\
\hline Total & 2 & 5 & 8 & 5 & 20 \\
\hline
\end{tabular}

Table 2. Where the patients kept their diabetic equipment

\begin{tabular}{llll}
\hline & $\begin{array}{l}\text { Needles } \\
n \text { subjects (\%) }\end{array}$ & $\begin{array}{l}\text { Syringes } \\
\boldsymbol{n} \text { subjects (\%) }\end{array}$ & $\begin{array}{l}\text { Other diabetic equipment } \\
\boldsymbol{n} \text { subjects (\%) }\end{array}$ \\
\hline Bedroom & $11(44)$ & $4(16)$ & $9(26)$ \\
Kitchen & $2(8)$ & $1(4)$ & $2(8)$ \\
Refrigerator & - & $14(56)$ & - \\
Dining room & $1(4)$ & $1(4)$ & $1(4)$ \\
Cupboard & $5(20)$ & $1(8)$ & $4(16)$ \\
Wardrobe & $3(12)$ & $2(4)$ & $3(12)$ \\
Drawer & $1(4)$ & $1(4)$ & - \\
Box & $1(4)$ & - & $1(4)$ \\
Cooler bag & $1(4)$ & $1(4)$ & $1(4)$ \\
N/A & - & - & $4(16)$ \\
Total & $25(100)$ & $25(100)$ & $25(100)$ \\
N/A = no regular place of storage. & & &
\end{tabular}

Table 3. Insulin storage

\begin{tabular}{lll}
\hline & $\begin{array}{l}\text { Overnight } \\
\boldsymbol{n} \text { subjects (\%) }\end{array}$ & $\begin{array}{l}\text { Daytime } \\
\boldsymbol{n} \text { subjects (\%) }\end{array}$ \\
\hline Refrigerator & $21(84)$ & $14(56)$ \\
Box & $1(4)$ & $2(8)$ \\
Kitchen & $1(4)$ & $1(4)$ \\
Other & $2(8)$ & $1(4)$ \\
Carry ${ }^{\star}$ plus fridge & 0 & $6(24)$ \\
Cooler bag plus fridge & 0 & $1(4)$ \\
Total & $25(100)$ & $25(100)$ \\
${ }^{*}$ Take to school or leisure activity. & &
\end{tabular}

the mothers, and in all cases technique was appropriate.

\section{Discussion}

Our clinic serves a periurban, lower socioeconomic, black African population. It is assumed, given the absence of reliable prevalence data, that type 1 diabetes is uncommon in black South Africans. In Tanzania, the annual incidence of type 1 diabetes in children was $1.5 / 100000 .^{[7]}$ Accordingly, the relatively small number of patients with type 1 diabetes in our clinic is not surprising.
Our patients' high HbAlc values reflect the lack of resources afforded diabetes mellitus at our hospital. The only diabetes educator in the hospital has more duties elsewhere than in the endocrinology service. It has been challenging to obtain analogue insulins, and we have not been allowed to use insulin pumps. Blood glucose testing strips are all too frequently out of stock. These challenges affect the choice of insulin therapy for our patients.

Giving premixed insulins twice a day is clearly not appropriate for the majority of patients, most of whom should be on 
Table 4. Measurement and administration of insulin

\begin{tabular}{llll}
\hline & $\begin{array}{l}\text { Who measures } \\
\text { insulin? } \\
n \text { subjects (\%) }\end{array}$ & $\begin{array}{l}\text { Who checks } \\
\text { insulin? } \\
\boldsymbol{n} \text { subjects (\%) }\end{array}$ & $\begin{array}{l}\text { Who administers } \\
\text { insulin? } \\
\boldsymbol{n} \text { subjects (\%) }\end{array}$ \\
\hline Mother & $5(20)$ & $4(16)$ & $2(8)$ \\
Mother (sometimes) & 0 & $1(4)$ & 0 \\
Self & $18(72)$ & 0 & $20(80)$ \\
Self and mother & $1(4)$ & 0 & $3(12)$ \\
Aunt & $1(4)$ & 0 & 0 \\
Sister & 0 & $1(4)$ & 0 \\
Schoolteacher & 0 & $1(4)$ & 0 \\
No one & 0 & $18^{*}(72)$ & 0 \\
Total & $25(100)$ & $25^{*}(100)$ & $25(100)$ \\
*This includes the 5 mothers who always measured the insulin. & &
\end{tabular}

Table 5. Home blood glucose testing

\begin{tabular}{lllll}
\hline & $\begin{array}{l}\text { Finger prick } \\
n \text { subjects (\%) }\end{array}$ & $\begin{array}{l}\text { Measure } \\
\text { results } \\
\boldsymbol{n} \text { subjects (\%) }\end{array}$ & $\begin{array}{l}\text { Check result } \\
\boldsymbol{n} \text { subjects (\%) }\end{array}$ & $\begin{array}{l}\text { Record results } \\
\boldsymbol{n} \text { subjects (\%) }\end{array}$ \\
\hline Mother & $4(16)$ & $4(16)$ & $3(12)$ & $3(12)$ \\
Mother (sometimes) & - & - & $1(4)$ & - \\
Self & $14(56)$ & $11(44)$ & - & $15(60)$ \\
Self and mother & $1(4)$ & $1.5(6)^{*}$ & - & - \\
Other family member & - & $2.5(10)^{*}$ & - & $1(4)$ \\
No one & $6(24)$ & $6(24)$ & $21(84)$ & $6(24)$ \\
Total & $25(100)$ & $25(100)$ & $25(100)$ & $25(100)$ \\
*In one case the patient was supervised either by the mother or another family member. &
\end{tabular}

multiple daily injections. Many more blood glucose testing strips should be supplied to enable HBGM at least three times a day. Insulin pump therapy may make management more convenient and avoid the many needle pricks, but according to Skogsberg et al. ${ }^{[8]}$ while there is improved patient satisfaction there is no difference in metabolic control with pump therapy v. multiple daily injections. Several metaanalyses show a statistical difference in favour of pump therapy, but only amounting to a minimal improvement of $0.2-0.3 \%$ in HbAlc values. ${ }^{[9-12]}$ Similarly, continuous subcutaneous glucose sensing devices exist to improve blood glucose control, but again by a clinically unimportant amount. ${ }^{[13]}$

It is gratifying that every one of our patients had access to a refrigerator. However, despite this some failed to store their insulin in the refrigerator, in an area where day temperatures are usually above $30^{\circ} \mathrm{C}$ in summer. Insulin should be stored in a refrigerator at $4-8^{\circ} \mathrm{C}$, and never frozen, or alternatively stored at an ambient temperature of $15-25^{\circ} \mathrm{C}$, which requires that any remaining insulin be discarded after 4 weeks. ${ }^{[3]}$

Assuming that patients who were on a twice-daily insulin regimen would not need to carry insulin with them, as they can have the first injection before breakfast and the second before supper, it was not clear why seven saw the need to take their insulin to school. In contrast, only two of the five patients who received three or four injections a day carried their insulin with them, perhaps because they returned home at lunchtime for their additional injection.

While measurement of the insulin dose is only moderately reliable when a vial and insulin syringe is used, with the Penset the correct amount can be dialled, so mistakes are usually only found early on (or in patients who are partially sighted). Indeed the technique was correct in all our cases, whether using syringes or the Penset. Most of the children had to measure their own insulin without help. This is clearly inappropriate, even in adolescence, and contrasts with a study in the UK where parents needed to reassure themselves by constant checking, to the extent that some children felt that their parents were too controlling. ${ }^{[1]}$

With the modern spring-loaded lancet devices, fingerprick testing is quite easy. In five cases the children were helped with fingerpricks, in eight with measuring their blood glucose results, and in four with both checking and recording their results.

\section{Conclusion}

The children in our study were rarely assisted by adults with either their insulin injections or HBGM, and are not sufficiently supported by their families.

Acknowledgements. Thanks are due to Dr $\mathrm{K}$ E Lengane, who conducted the interviews in English and in Tswana, and to Gillian K de Villiers who performed data entry and analysis.

\section{References}

1. Marshall M, Carter B, Rose K, Brotherton A. Living with type I diabetes: Perceptions of children and their parents. J Clin Nurs 2009;18(12):1703-1710. [http://dx.doi.org/10.1111/j.13652701.2008.02737.x]

2. Harris ST, Pokorny ME. Living with diabetes: What patients are saying. Care Manag J 2012;13(2):46-50. [http://dx.doi. org/10.1891/1521-0987.13.2.46]

3. Bangstad H-J, Danne T, Deeb L, Jarosz PC, Urakami T, Hanas R. ISPAD Clinical Practice Consensus Guidelines 2009: Insulin R. ISPAD Clinical Practice Consensus Guidelines 2009: Insulin
treatment in children and adolescents with diabetes. Pediatr treatment in children and adolescents with diabetes. Pediatr
Diabetes 2009;10(Suppl 12):82-99. [http://dx.doi.org/10.1111/ Diabetes 2009;10(Suppl 12):82
j.1399-5448.2009.00578.x]

j.1399-5448.2009.00578.x]
4. Chase PH, Maahs D. Responsibilities of children at different ages. In: Chase HP, Maahs D. Understanding Diabetes. 12th ed. 2012. Denver, CO: Pink Panther Books, University of Colorado, 2012:ch. 18.

5. Aziz S. Recurrent use of disposable syringe-needle units in diabetic children. Diabetes Care 1984;7(2):118-120. [http:// dx.doi.org/10.2337/diacare.7.2.118

6. Islam MS, Ali SM. Multiple re-use of disposable insulin syringes in hospital. Bangladesh Medical Research Council Bulletin 1990;16(2):58-61.

7. Swai AB, Lutale JL, McLarty DG. Prospective study of incidence of juvenile diabetes mellitus over 10 years in Dar es Salaam, of juvenile diabetes mellitus over ) years in ar es Salaam,
Tanzania. BMJ 1993;306(6892):1570-1572. [http://dx.doi. Tanzania. BMJ 1993;306(6892)

8. Skogsberg L, Fors H, Hanas R, Chaplin JE, Lindman E, Skogsberg L, Fors $\mathrm{H}$, Hanas R, Chaplin JE, Lindman E,
Skogsberg J. Improved treatment satisfaction but no difference in metabolic control when using continuous subcutaneous insulin infusion vs. multiple daily injections in children at onset of type I diabetes mellitus. Pediatr Diabetes 2008;9(5):472-479. [http://dx.doi.org/10.1111/j.1399-5448.2008.00390.x]

9. Jeitler K, Horvath K, Berghold A, et al. Continuous subcutaneous insulin infusion versus multiple daily insulin injections in patients with diabetes mellitus: Systematic review and meta-analysis. Diabetologia 2008;51(6):941-951. [http:// dx.doi.org/10.1007/s00125-008-0974-3]

10. Monami M, Lamanna C, Marchionni N, Mannucci E. Continuous subcutaneous insulin infusion versus multiple daily insulin injections in type 1 diabetes: A meta-analysis. Acta Diabetol 2010;47(Suppl 1):S77-S81. [http://dx.doi.org/10.1007/ s00592-009-0132-5]

11. Pankowska E, Blazik M, Dziechciarz P, Szypowska A, Szajewska $\mathrm{H}$. Continuous subcutaneous insulin infusion vs. multiple daily injections in children with type 1 diabetes: A systematic review and meta-analysis of randomized control trials. Pediatr Diabetes 2009:10(1):52-58. [http://dx.doi.org/10.1111/j.13995448.2008.00440.x]

12. Pickup JC, Sutton AJ. Severe hypoglycaemia and glycaemic control in type 1 diabetes: Meta-analysis of multiple daily insulin injections compared with continuous subcutaneous insulin infusion. Diabet Med 2008;25(7):765-774. [http://dx.doi. org/10.1111/j.1464-5491.2008.02486.x]

13. Langendam M, Luijf YM, Hooft L, DeVries JH, Mudde AH, Langendam M, Luiff YM, Hoof $L$, DeVries $J H$, Mudde AH, Scholten RJM. Continuous glucose monitoring systems for type 1 diabetes mellitus. Cochrane Database Syst Rev 2012, Issue 1. Art. No.: CD008101. [http://dx.doi.org/10.1002/14651858.
CD008101.pub2]

Accepted 18 March 2015. 